\title{
Popper, panic and the Perhapsatron: arguments for small science
}

\author{
Neil Winterton
}

Published online: 2 September 2008

(C) Springer-Verlag 2008

It is difficult to improve upon Karl Popper's description of the pace and difficulty of technological progress, and its twin dependence on invention and discovery, when he said (Bondi 1992): 'We advance like a person walking through a swamp, first painfully on one leg and advancing it, and then on the other. One leg is labelled 'technology' and the other 'science".

Popper's words came to mind (with several other thoughts!) when, in the space of a few days, I read about the difficulties in international efforts to develop fusion energy generation (Brumfiel 2008a; Clery 2008a, 2008b; Editorial 2008), a call from a UK academic funding agency for suggested long-term (20-40 years) challenges (EPSRC 2008) and an article that appeared in the UK newspaper, The Guardian, on 1 August, (Simms 2008a) with the headline 'The final countdown'.

The Guardian article was promoted with the apocalyptic message that we have just ' 100 months to save the world'. The ' 100 months' is the time the authors, a 'group of global warming experts', suggest it will take for the carbon dioxide content of the atmosphere [actually, $\mathrm{CO}_{2} \mathrm{e}$, a calculated carbon dioxide equivalent (Simms 2008b)] to reach the 'tipping point', beyond which 'potentially' irreversible changes will occur in the climate system. I am not a climate scientist or even a global warming expert (with or without inverted commas). However, I wonder what the contributors to the 4th Assessment Report of the Intergovernmental Panel on Climate Change, whose data are the basis of the calculation, make of the precision of this estimate and the failure to provide measures of the associated uncertainty.

N. Winterton $(\bowtie)$

Department of Chemistry, University of Liverpool,

Liverpool L69 7ZD, UK

e-mail: N.Winterton@liverpool.ac.uk
Nor is there any discussion of the different probabilities of irreversible effects arising from exceeding the critical $\mathrm{CO}_{2}$ concentration for 5,50 or 500 years, before bringing it back below this level. For a better argued pair of (different!) perspectives on the climate change debate, the reader could do much worse than read James Lovelock's polemic, 'Revenge of Gaia' (Lovelock 2006) and Bjørn Lomborg's 'Cool It' (Lomborg 2007).

The Guardian article is typical of those that use science to underpin scary scenarios about climate change to catch public attention. From a reading of the 431 subsequent comments on the Guardian website (Guardian 2008) few minds have been changed. Indeed, the 100 month estimate seems to have been received with derision in some quarters and could deflect attention away from the more serious points the authors seek to make. The authors, from the New Economics Foundation, suggest that resource use should be cut, by 're-engineering' the UK economy along the austerity and command lines of the Second World War. They believe that the UK government should unilaterally set an example by not permitting the building of the third runway at London's Heathrow airport nor the new coal-fired power station in the county of Kent. They also believe that developing countries would then follow this example.

Perhaps significantly, the article failed to make any mention at all of the availability of a developed, effective and readily deployable alternative technology, namely nuclear fission, that might aid the controlling of anthropogenic $\mathrm{CO}_{2}$ emissions as part of the transition to more sustainable energy-generating technologies. Nor, following the logic of the 100 month argument, was there any call to divert funding away from fusion research, whose development into a workable and deployed technology is only likely to appear in 3-400 months, if then, long after the supposed 'tipping point'. This set me thinking about the 
mind-set of those in, or encouraging, panic mode and the (more serious) effect such panic could have on decisionmakers responsible for managing Popper's walk through the climate change swamp, that is, the difficult process of effecting the transition to more sustainable ways of living.

Governments, seeking to manage their budgets and fiscal policies to address the consequences of the credit crunch and the impact on their economies of increased basic raw material costs, may well be tempted to cut funding of research programmes, particularly those focusing on the fundamental and long-term. That those in power (and those seeking to replace them) should tend to be focused on electoral timescales that are short compared with those needed to bring about major technological (or any other) change is a price to be paid by those living in democracies, in which politicians are permitted power for relatively short periods.

Funding for long-term science could, therefore, be seen as politically something of an altruistic act. In the UK, support for science (Blair 1998) was expressed early in the Blair government. Research funding has increased nearly two-fold in real terms since 1997 (Brumfiel 2008b). Not unexpectedly, and quite reasonably, the government expects some return on this investment. In times of financial stringency, 'selectivity' (that is, focussing on relevance, application, the shorter-term and the less adventurous) will become more politically expedient. Angry and critical responses from scientists can often be made to appear simply self-serving and may be self-defeating.

In June, the UK's Engineering and Physical Sciences Research Council (EPSRC) called on chemists (and others) 'to look 20-40 years in the future and think what could be achieved on this timescale if researchers, from different research groups, disciplines or institutions, were to work together' (EPSRC 2008). This process of participation in programme development startled me somewhat as it coincided with a serious reduction in the amount of money available for so-called 'responsive mode' or curiosity-driven projects in chemistry. Are not academic scientists already at least aware of the grand challenges? Will not many of them be working on them (or some part of them)? And if not, why not? Was this a career play by a funding agency bureaucrat? Or, was it an attempt to get the attention of ministers or senior civil servants to protect funding for science (much more laudable!) in times of greater financial stringency?

While the objectives of the EPSRC initiative may be worthy (and no scientist is going to refuse the opportunity to secure research funding), it is pertinent to ask whether it is sensible at all to focus on developmental outcomes as long in the future as 40 years. The record of accomplishment of those seeking to do so is not good. Ernest Rutherford's suggestion that 'anyone who expects a source of power from the transformation of the atom is talking moonshine' was proved incorrect only ten years afterwards when Enrico Fermi demonstrated controlled nuclear fission. It is, more often than not, impossible either to anticipate enabling developments that might later be applied or to predict the applications to which a new scientific discovery might ultimately give rise. Hindsight, or the selective remembering of history, can often give a false perspective, particularly to those who were not closely involved. It is rare to be able to predict outcomes: indeed, many scientific advances arise serendipitously. Funding agencies take this insufficiently into account, the more so as their management becomes more influenced by government and civil servants.

Synergies or growth points arise accidentally and, sometimes, from unexpected quarters. The serendipitous discovery of $\mathrm{C}_{60}$ did not arise from an 'initiative' or a 'programme' (nor even from organic chemistry), but from an inspired curiosity-driven collaboration (Kroto 1996). A revealing example, highlighting the unplanned outcome of exploratory research in industry, arises from Fraser Stoddart's seminal contributions (Stoddart and Colquhoun 2008) to the current 'hot' area of molecular machines. His work on host-guest chemistry itself grew out of piece of speculative product development done during a period at ICI's Corporate Laboratory in the early 1980s, when he tried to find a safener for the herbicide, diquat.

Likewise, much research, not believed to have any use when it was first done, later led to developments with immense scientific and societal impact. For example, in 1922 Otto Stern and Walther Gerlach (Friedrich and Herschbach 2003) provided experimental observations, which later were seen to arise from the fundamental property of nuclear spin. Subsequent work by Isidor Rabi led to the discovery of the phenomenon of nuclear magnetic resonance, which itself had the most profound consequences in chemistry and, later, was exploited in the non-invasive technique of Magnetic Resonance Imaging (for which Paul C. Lauterbur and Sir Peter Mansfield shared the 2003 Nobel Prize for medicine). No one supporting Stern and Gerlach's work at the time would have expected them to anticipate these later scientific and technological developments.

In a science-based industry, such as the chemical industry, there is always a need to have a pipeline of $R \& D$ projects (of different scope, timescale and magnitude) combined with sufficient agility to shift direction when an unforeseen eventuality arises or when a change of strategy is called for. However, even under these circumstances, when industry demands profitable or potentially profitable outcomes, the far-sighted business understands the critical importance for its health, and indeed its survival, of having in-house scientists and technologists, involved in R\&D with an eye on the longer term. Government-funded research 
likewise requires a portfolio of both curiosity-driven research and that directed towards problem solving, and political support and operational management that appreciates and understands its importance, not least to protect the portfolio from well-organised single-issue campaigns and the associated short-term political pressures.

How tempted will politicians around the world be to cut funding in the face of increases in (already huge) budgets and (already extended) timescales (Brumfiel 2008a; Clery 2008a, 2008b; Editorial 2008) of the international fusion project, ITER (International Thermonuclear Experimental Reactor)? In the US, one related project has been shut down because of increased costs and delays (Cho 2008). I am old enough (just!) to remember articles in the press claiming (somewhat prematurely, it turned out) the success of UK's ZETA project which held out the prospect of inexhaustible supplies of cheap and safe energy from nuclear fusion. Later work established that the optimism was unfounded and the ZETA project closed in 1958. One of the first US experimental fusion reactors, built in the early 1950s, was whimsically called the 'Perhapsatron' (Phillips 1983) suggesting that, at the time, scientists were not required to state when their development would become technologically realisable. I indeed hope that the ITER programme will continue because of the long-term and profound benefits its success would make possible. However, if science budgets are to be trimmed, I would not like to see other, smaller, projects abandoned, or fail to be funded, simply to protect ITER in its entirety, important as its objectives are.

Big science is increasingly having to justify itself in terms of budgets and timescales-not necessarily a bad thing. Big programmes attract attention. Reputations and promotions can follow. However, big projects can lead to big mistakes. Big programmes also require big money and tend to require big administration and support budgets. They are also much harder to stop. Perhaps, now could be the time to enhance the attention given to 'small' science. Small science can be significantly less expensive, but still provides the biggest of intellectual challenges across the widest of horizons. It can support a large number of disparate projects and scientists and can keep costs of programme oversight down, ensuring more research bang for the buck. In addition, the inevitable mistakes are made on the small scale. Scientists will be quick to spot areas of excitement and potential and provide the stimulus for development and exploitation. Unfortunately, successes in small science, that later turn out to have been immensely significant, do not always make the headlines at the time. However, they can provide the critical understanding needed to enable a technology to arise or become economically and commercially realisable.

Are there not aspects of the search for energy sources as alternatives for those that are fossil-derived or aspects of the understanding of the natural world (and the impact that humankind is having on it) that might benefit from some additional small, curiosity-driven, science? Who knows, such research might unexpectedly result in a bigger and quicker return than some more expensive longer-term programmes.

Large-scale implementation of alternative energy technologies that can substitute for those based on fossil resources, and its more rapid full scale and economic application, will also need the input of small science: from engineers and material scientists (for wind power); physicists and engineers (nuclear fission), biologists, chemists and agronomists (biofuels); physicists, material scientists and chemists (solar cells). Will this support be forthcoming? I would argue that protecting (at least) that part of the annual budget devoted to (relatively) small science, keeping the basic underpinning disciplines of chemistry, physics, biology, engineering alive and well during straightened times, will more than repay itself in aiding the hard struggle for technological progress through Popper's swamp.

\section{References}

Blair T (1998) UK Science Funding Increase. Science 281:1141

Bondi H (1992) The philosopher for science. Nature 358:363

Brumfiel G (2008a) Fusion reactor faces cost hike. Nature 453:829

Brumfiel G (2008b) Payback time. Nature 453:1150

Cho A (2008) Energy department pulls plug on overbudget fusion experiment. Science 320:1142

Clery D (2008a) Design changes will increase ITER reactor's cost. Science 320:1405

Clery D (2008b) ITER costs give partners pause. Science 320:1707

Editorial (2008) The price isn't right. Nature 453:824

EPSRC (2008) Consultation on grand challenges in chemical sciences and engineering. http://www.epsrc.ac.uk/CMSWeb/Downloads/ Other/ConsGrandChallengesChemSciEng.pdf

Friedrich B, Herschbach D (2003) Stern and Gerlach: how a bad cigar helped reorient atomic physics. Physics Today 56:53 (December)

Guardian (2008) http://www.guardian.co.uk/commentisfree

Kroto HW (1996) Symmetry, space, stars and $C_{60}$. Nobel Lecture, 7 December 1996. http://nobelprize.org/nobel_prizes/chemistry/ laureates/1996/kroto-lecture.pdf

Lomborg B (2007) Cool it: the skeptical environmentalist's guide to global warming. Alfred A Knopf, New York

Lovelock J (2006) The revenge of Gaia's: earth's climate crisis and the fate of humanity. Basic Books

Phillips JA (1983) Magnetic fusion. Los Alomos Science Winter/Spring 1983 p 64. http://library.lanl.gov/cgi.bin/getfile?00285870.pdf

Simms A (2008a) The final countdown. The Guardian G2 Section, p 6-9, 1 August 2008

Simms A (2008b) '100 months: technical note'. http://www. onehundredmonths.org

Stoddart JF, Colquhoun HM (2008) Big and little meccano. Tetrahedron 64:8231 